\title{
Performance comparison of SVC and SSSC with POD controller for Power System Stability
}

\author{
K. Kalyan Kumar ${ }^{1}$, V. Shararth Babu², M. Hari Babu ${ }^{3}$, R. Bhaskar ${ }^{4}$ \\ 1, 2, 3, 4 (EEE, Vardhaman College of Engineering (Autonomous), India)
}

\begin{abstract}
Steady state and transient problems in a power system have undesirable consequences on the system. It can limit the amount of power that can be transmitted in the system and consequently leads to voltage instability and at times it may also result into total voltage collapse.The main objective of this paper is a comparative investigate in enhancement of volatge stability via static synchronous series compensator (SSSC) and static var compensator (SVC) externally controlled by a POD controller.The new designed P.O.D controller is very efficient for voltage stability under transient conditions. This paper discusses and demonstrates the comparision between the SVC with P.O.D controller and SSSC with P.O.D controller,applied to power system for effectively regulating system voltage for different types of faulted condition. One of the major reasons for installing a SVC is to improve dynamic voltage control and thus increase system load ability during transient condition. This work is presented to present the transmission line voltage stability \& machine oscillation damping stability by using SVC \& SSSC with POD controller \& compared their performance to enhance the stability of a power system. Simulation results shows that SVC with POD controller is more effective to enhance the voltage stability and increase transmission capacity in a power system.
\end{abstract}

Keywords- FACTS,Power system, POD Controller,SVC(Static VAR compensator), SSSC(static synchronous series compensator), Voltage Stability.

\section{INTRODUCTION}

Today's changing electric power systems create a growing need for flexibility, reliability, fast response and accuracy in the fields of electric power generation, transmission, distribution and consumption. Flexible Alternating Current Transmission Systems (FACTS) are new devices emanating from recent innovative technologies that are capable of altering voltage, phase angle and/or impedance at particular points in power systems. Their fast response offers a high potential for power system stability enhancement apart from steadystate flow control. Since then the large effort was put in research and development of FACTS controllers. Static Synchronous Compensator (STATCOM), Static Synchronous Series Compensator (SSSC) and Unified Power Flow Controller (UPFC) etc., bus voltages, line impedances and phase angles in the power system can be regulated rapidly and flexibly. These FACTS controllers are based on voltage source converters. Thus, FACTS can facilitate the power flow control, enhance the power transfer capability, decrease the generation cost, and improve the security and stability of the power system. Among the FACTS controllers, Static Var Compensator (SVC) provides fast acting dynamic reactive compensation for voltage support during contingency events which would otherwise depress the voltage for a significant length of time.SVC also dampens power swings and reduces system losses by optimized reactive power control. In previous works the effective methods of control have been implemented to control of SVC in order to damp power swings.

A Static Synchronous Series Compensator (SSSC) is another member of FACTS family which is connected in series with a power system. It consists of a solid state voltage source converter which generates a controllable alternating current voltage at fundamental frequency. When the injected voltage is kept in quadrature with the line current, it can emulate as inductive or capacitive reactance so as to influence the power flow through the transmission line. While the primary purpose of a SSSC is to control power flow in steady state, it can also improve transient stability of a power system. SSSC is proposed as the most adequate for the present application well discussed [1]. The DC inner bus of the SSSC allows incorporating a substantial amount of energy storage in order to enlarge the degrees of freedom of the SSSC device and also to exchange active and reactive power with utility grid.

A Power Oscillation Damping (POD) controller with a conventional structure is installed on the SSSC to improve the system dynamic behavior. The damping of power oscillations by static synchronous series compensator (SSSC) based damping controllers. The advantage of this approach is that it can handle the nonlinearities, at the same time it is faster than other conventional controllers and it improve the reactive power of the system. Simulation studies are carried out in Matlab/Simulink environment to evaluate the effectiveness of the proposed Static synchronous series compensator (SSSC) based on the POD controller. The proposed SSSC based damping controllers improve the damping performance of the system in the event of a major disturbance. 
MATLAB/SIMULINK used in this study to conduct simulations on voltage regulation at the point of connection of SVC \& SSSC with POD controller to the system. However, the aim of this paper is to compare the performances of SVC \& SSSC with POD controller to enhance voltage stability at the event of occurrence of fault in the system. Among the available FACTS devices, the Unified Power Flow Controller (UPFC) is the most versatile one that can be used to improve steady state stability, dynamic stability and transient stability [4]. The UPFC can independently control many parameters since it is the combination of Static Synchronous Compensator (STATCOM) and SSSC. These devices offer an alternative mean to mitigate power system oscillations. It has been reported in many papers that UPFC can improve stability of single machine infinite bus (SMIB) system and multimachine system [5]-[6]. The inter-area power system has special characteristic of stability behaviour [19].

\section{Concept Of Svc}

An SVC is a controlled shunt susceptance (B) which inject reactive power $\left(Q_{n e t}\right)$ into thereby increasing the bus voltage back to its net desired voltage level. If bus voltage increases, the SVC will inject less (or TCR will absorb more) reactive power, and the result will be to achieve the desired bus vol-tage. Fig.1, represents SVC based control system with AVR, \& POD controller.

SVC (AVR) controller always monitor the bus vol-tage $\left(\mathrm{V}_{\mathrm{svc}}\right)$ \& current (Isvc), it compare the actual bus voltage with $V_{\text {ref }}$ \& taking error voltage, $V_{\text {error }}=V_{\text {ref }}-V_{a}-\left(I_{s v c} * X_{s l}\right) \&$ integrate it in limit (-Q $Q_{\text {cap }}$ to $\left.+Q_{\text {ind }}\right)$, the net susceptance has been produced which control the pulse generator \& Thus TCR \& TSC are controlled \& voltage becomes stable to-wards it's Vref shown in Fig.1 [7-8].

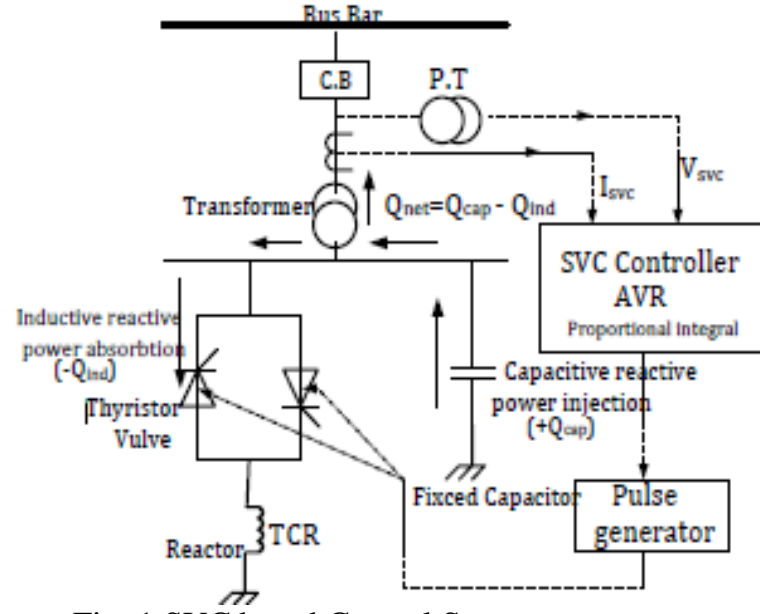

Fig. 1 SVC based Control System

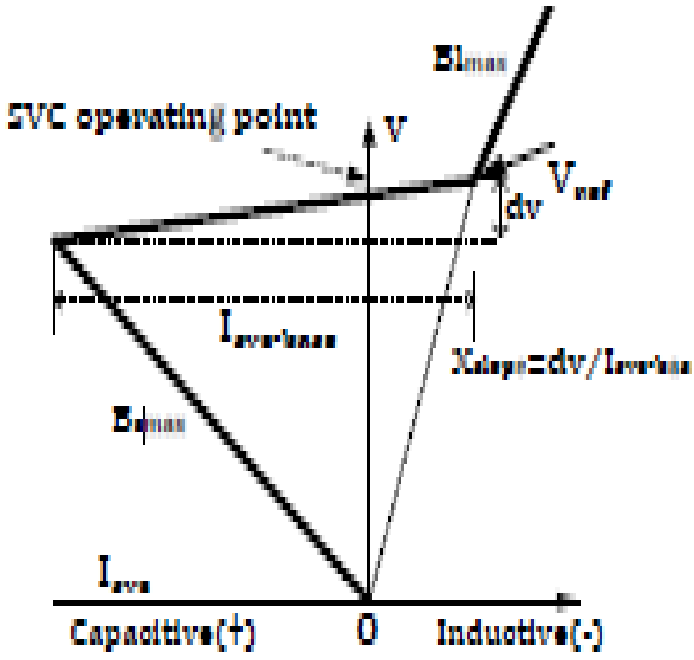

Fig. 2 Steady state(V-I) characteristics of a SVC

\subsection{SVC V-I Characteristic}

The SVC can be operated in two different modes:

a). In voltage regulation mode (the voltage is regulated with-in limits as explained below).

b). In VAR control mode (the SVC susceptance is kept con-stant). From V-I curve of SVC, From Fig.3,

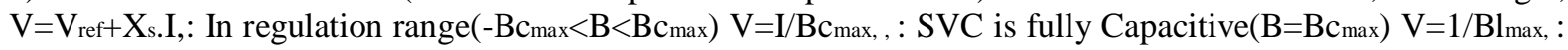
$\mathrm{SVC}$ is fully inductive $\left(\mathrm{B}=\mathrm{B} l_{\max }\right)$

\subsection{SVC Structure}

Electrical loads both generate and absorb reactive power. Since the transmitted load varies considerably from one hour to another, the reactive power balance in a grid varies as well. The result can be unacceptable voltage amplitude variations or even a voltage depression, at the extreme a voltage collapse. A rapidly operating Static Var Compensator (SVC) can continuously provide the reactive power required to control dynamic voltage oscillations under various system conditions and thereby improve the power system transmission and distribution stability. Installing an SVC at one or more suitable points in the network can increase transfer capability and reduce losses while maintaining a smooth voltage profile under different network conditions. In addition an SVC can mitigate active power oscillations through voltage amplitude modulation. SVC installations consist of a number of building blocks. The most important is the Thyristor valve, i.e. stack assemblies of series connected anti-parallel Thyristors to provide controllability.

Air core reactors and high voltage AC capacitors are the reactive power elements used together with the Thyristor valves. The step up connection of this equipment to the transmission voltage is achieved through a power transformer. The Thyristor valves together with auxiliary systems are located indoors in an SVC building, 
while the air core reactors and capacitors, together with the power transformer are located outdoors. In principle the SVC consists of Thyristor Switched Capacitors (TSC) and Thyristor Switched or Controlled Reactors (TSR / TCR). The coordinated control of a combination of these branches varies the reactive power as shown in Fig. 3.
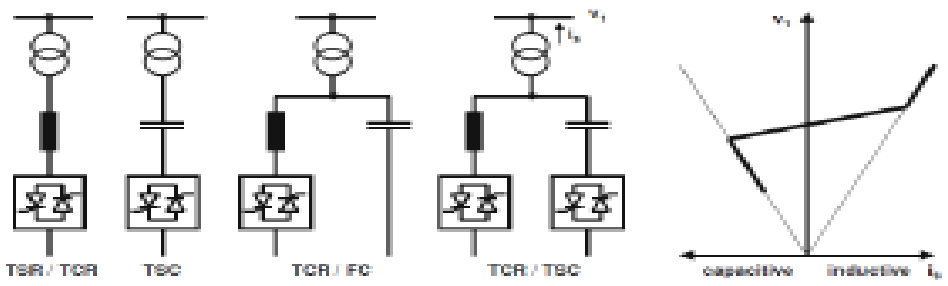

Fig. 3 SVC Building blocks and voltage / Current characteristics

The first commercial SVC was installed in 1972 for an electric arc furnace. On transmission level the first SVC was used in 1979. Since then it is widely used and the most accepted FACTS-device

\subsection{Network modeling with SVC}

This example described in this section illustrates modeling of a simple transmission system containing two hydraulic power plants. Static VAR compensator (SVC) has been used to improve voltage stability and power system oscillations damping. A single line diagram represents a simple $500 \mathrm{kV}$ transmission system is shown in Fig. 4.

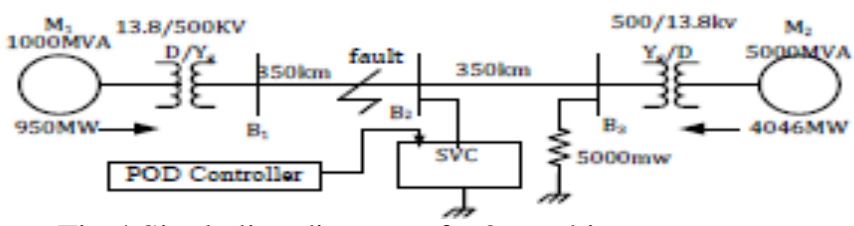

Fig.4 Single line diagram of a 2-machine power system

\subsection{Operating principle of SSSC}

\section{Static Synchronous Series Compensator (SSSC)}

The SSSC is one of the most recent FACTS devices for power transmission series compensation. It can be considered as a synchronous voltage source as it can inject an almost sinusoidal voltage of variable and controllable amplitude and phase angle in series with a transmission line. The injected voltage is almost in quadrature with the line current. A small part of the injected voltage that is in phase with the line current provides the losses in the inverter. Most of the injected voltage, which is in quadrature with the line current, provides the effect of inserting an inductive or capacitive reactance in series with the transmission line. The variable reactance influences the electric power flow in the transmission line. The basic configuration of a SSSC is shown in Fig. 5

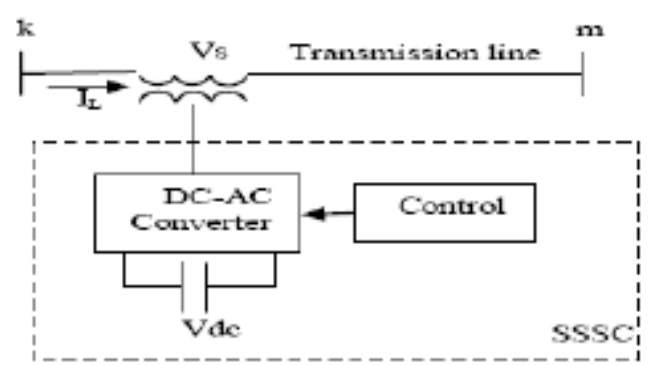

Fig.5 Simplified diagram of a SSSC

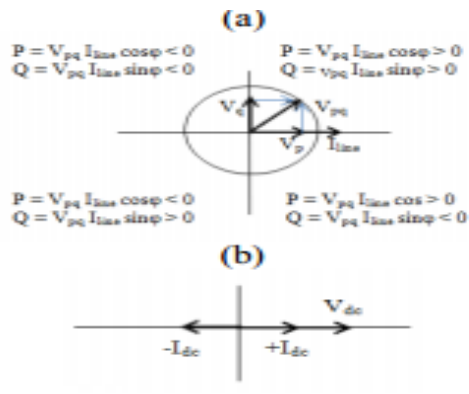

Fig.6 SSSC Phasor diagram

Theoretically, SSSC operation in each of the four quadrants is possible, Theoretically, SSSC operation in each of the four quadrants is possible, but there are some limitations to the injected SSSC voltage due to operating constraints of practical power system. In capacitive mode, the injected SSSC voltage is made to lag the transmission line current by $90^{\circ}$; in this case, the SSSC operation is similar to the operation of a series capacitor with variable capacitance $\mathrm{kXc}$, i.e., $\mathrm{Vpq}=-\mathrm{jKXcI}_{\mathrm{lin}}$, where $\mathrm{k}$ is a variable.

\subsection{Rating of the SSSC}

The SSSC can provide capacitive or inductive compensating voltage independent of the line current. The VA rating of the SSSC (solid-state inverter and coupling transformer) is simplythe product of the maximum 
line current (at which compensation is still desired) and the maximum series compensating voltage: $\mathrm{VA}=$ $I_{\max } V_{\max }$. An SSSC of 1 p.u. VA rating covers a control range corresponding to 2 p.u. compensating VARs, that is the control range is continuous from -1 p.u. (inductive) VARs to +1 p.u. (capacitive) VARs.

\subsection{Internal Controls}

From the standpoint of output voltage control, converters may be categorized as "directly" and "indirectly" controlled. For directly controlled converters both the angular position and the magnitude of the output voltage are controllable by appropriate valve (on and off) gating. For indirectly controlled converters only the angular position of the output voltage is controllable by valve gating; the magnitude remains proportional to the dc terminal voltage. The control method of maintaining a quadrature relationship between the instantaneous converter voltage and line current vectors, to provide reactive series compensation and handle SSR, can be implemented with an indirectly controlled converter. The method of maintaining a single frequency synchronous (i.e. fundamental) output independent of dc terminal voltage variation requires a directly controlled converter. Although high power directly controlled converters are more difficult and costly to implement than indirectly controlled converters (because their greater control flexibility is usually associated with some penalty in terms of increased losses, greater circuit complexity, and/or increased harmonic content in the output), nevertheless they can be realized to meet practical utility requirements.

The SSSC, in series with line is capable of injecting up to $10 \%$ of the nominal system voltage. The SSSC injected voltage reference is normally set by a POD (Power Oscillation Damping) controller whose output is connected to the Vqref input of the SSSC. The POD controller consists of an active power measurement system, a general gain, a low-pass filter, a washout high-pass filter, a lead compensator, and an output limiter. The inputs to the POD controller are the bus voltage and the current flowing in Line.

\subsection{SSSC with POD Controller}

\section{Test System Description}

The power grid consists of two power generation substations and one major load center at bus B3. The first power generation substation (M1) has a rating of $2100 \mathrm{MVA}$, representing 6 machines of $350 \mathrm{MVA}$ and the other one (M2) has a rating of 1400 MVA, representing 4 machines of 350 MVA. The load center of approximately $2200 \mathrm{MW}$ is modeled using a dynamic load model where the active \& reactive power absorbed by the load is a function of the system voltage. The generation substation M1 is connected to this load by two transmission lines L1 and L2. L1 is $280-\mathrm{km}$ long and L2 is split in two segments of $150 \mathrm{~km}$ in order to simulate a three-phase fault (using a fault breaker) at the midpoint of the line. The generation substation M2 is also connected to the load by a 50-km line (L3). When the SSSC is bypass, the power flow towards this major load is as follows: $664 \mathrm{MW}$ flow on L1 (measured at bus B2), $563 \mathrm{MW}$ flow on L2 (measured at B4) and $990 \mathrm{MW}$ flow on L3 (measured at B3).

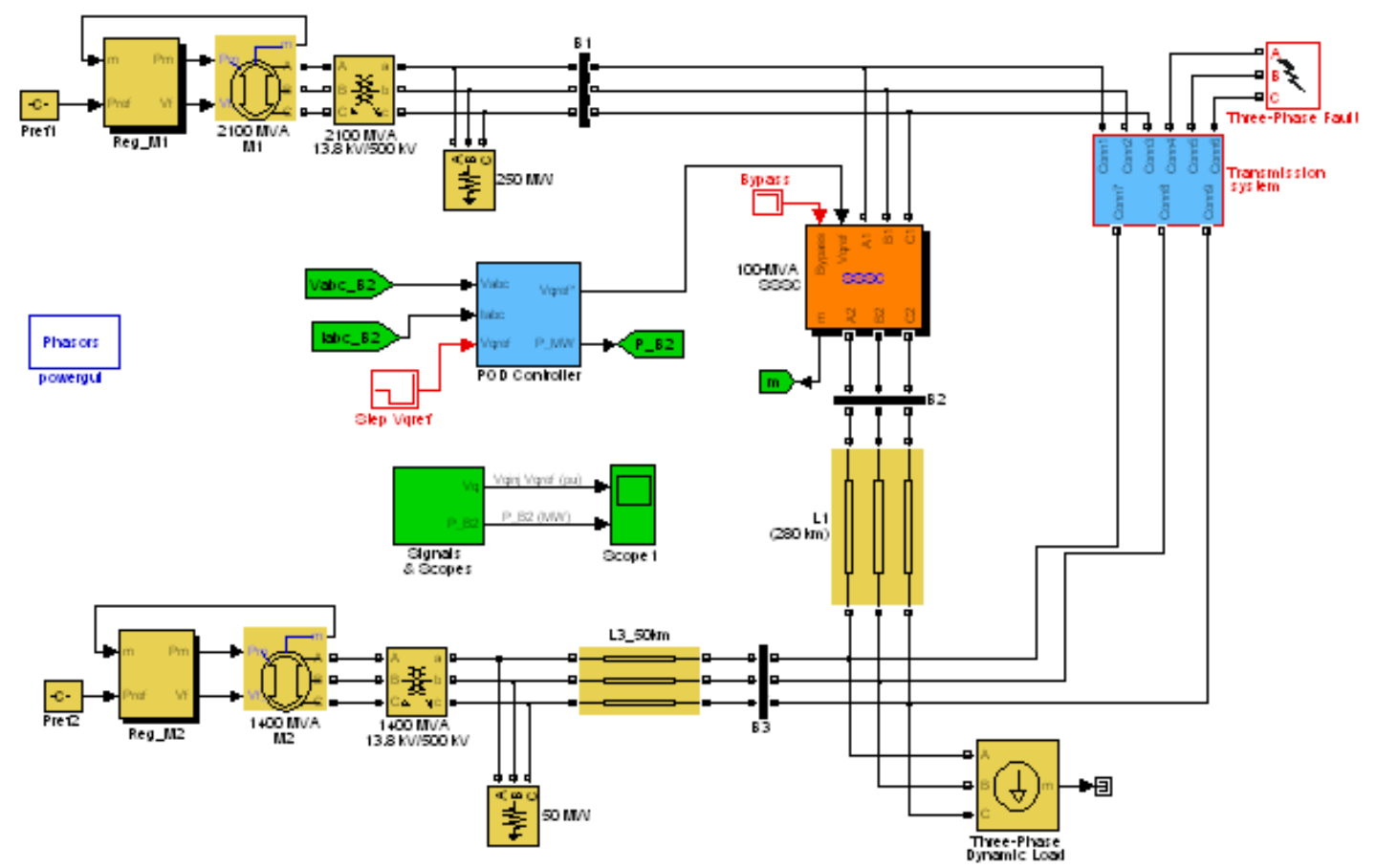

Fig. 7 Simulation Diagram of the SSSC 
The SSSC, located at bus B1, is in series with line L1. It has a rating of 100MVA and is capable of injecting up to $10 \%$ of the nominal system voltage. This SSSC is a phasor model of a typical three-level PWM SSSC. The model represents a SSSC having a DC link nominal voltage of $40 \mathrm{kV}$ with an equivalent capacitance of $375 \mathrm{uF}$. On the AC side, its total equivalent impedance is $0.16 \mathrm{pu}$ on $100 \mathrm{MVA}$. This impedance represents the transformer leakage reactance and the phase reactor of the IGBT bridge of an actual PWM SSSC. The SSSC injected voltage reference is normally set by a POD (Power Oscillation Damping) controller whose output is connected to the Vqref input of the SSSC. The POD controller consists of an active power measurement system, a general gain, a low-pass filter, a washout high-pass filter, a lead compensator, and an output limiter. The inputs to the POD controller are the bus voltage at B2 and the current flowing in L1.

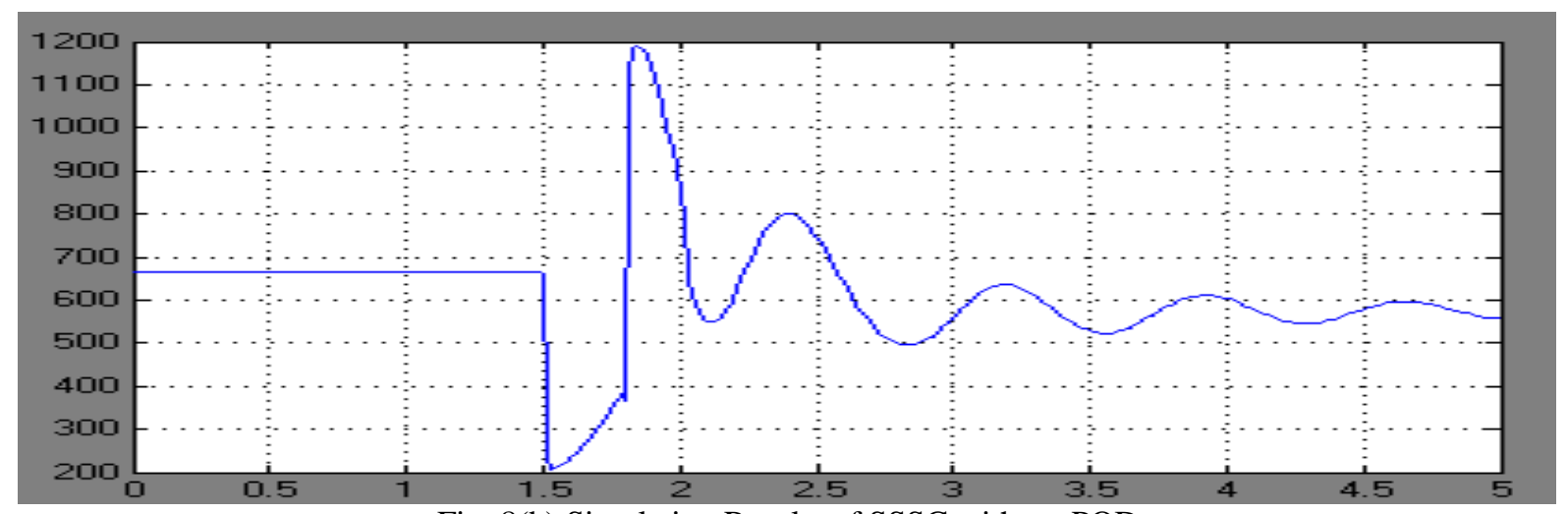

Fig. 8(b) Simulation Results of SSSC without POD

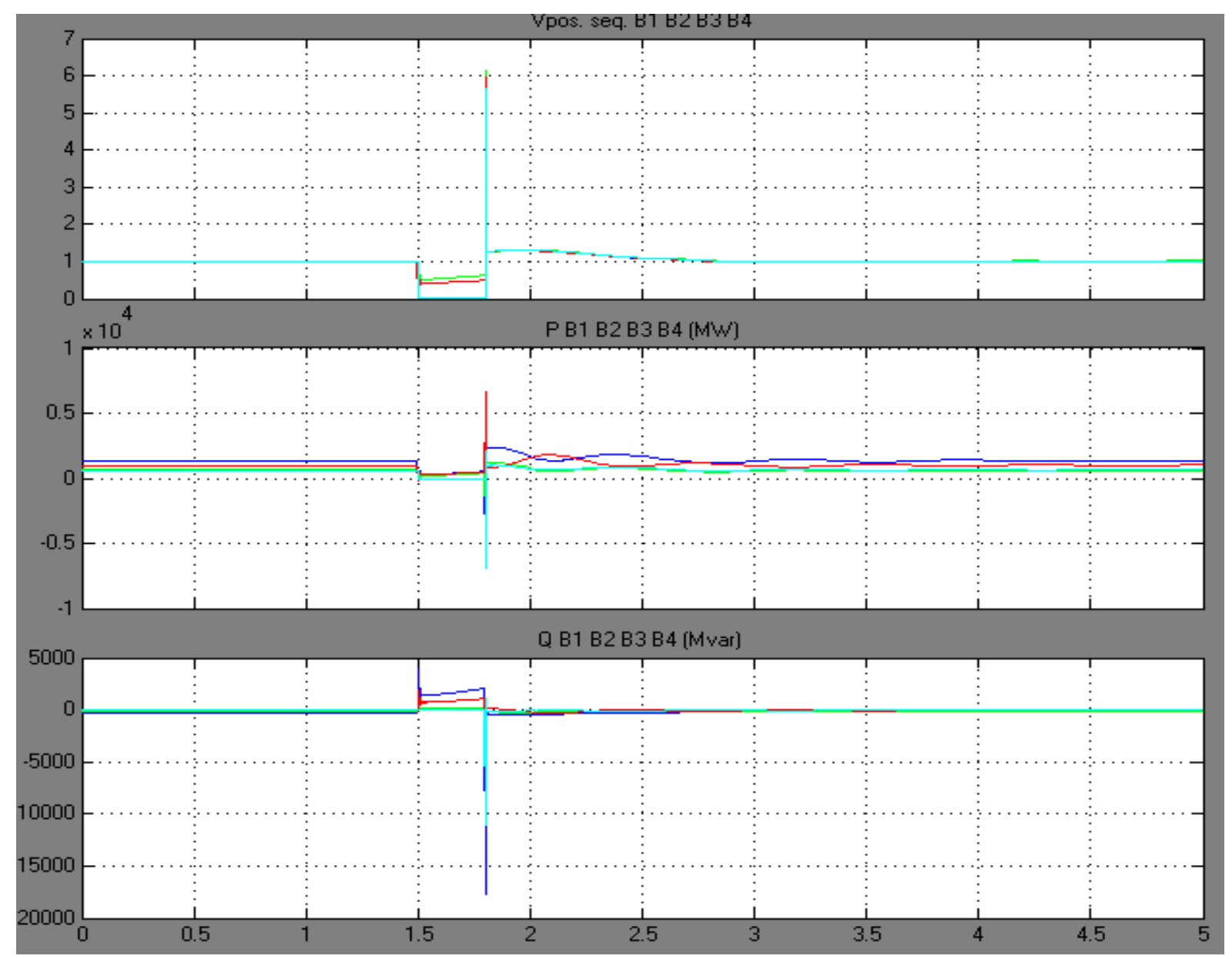




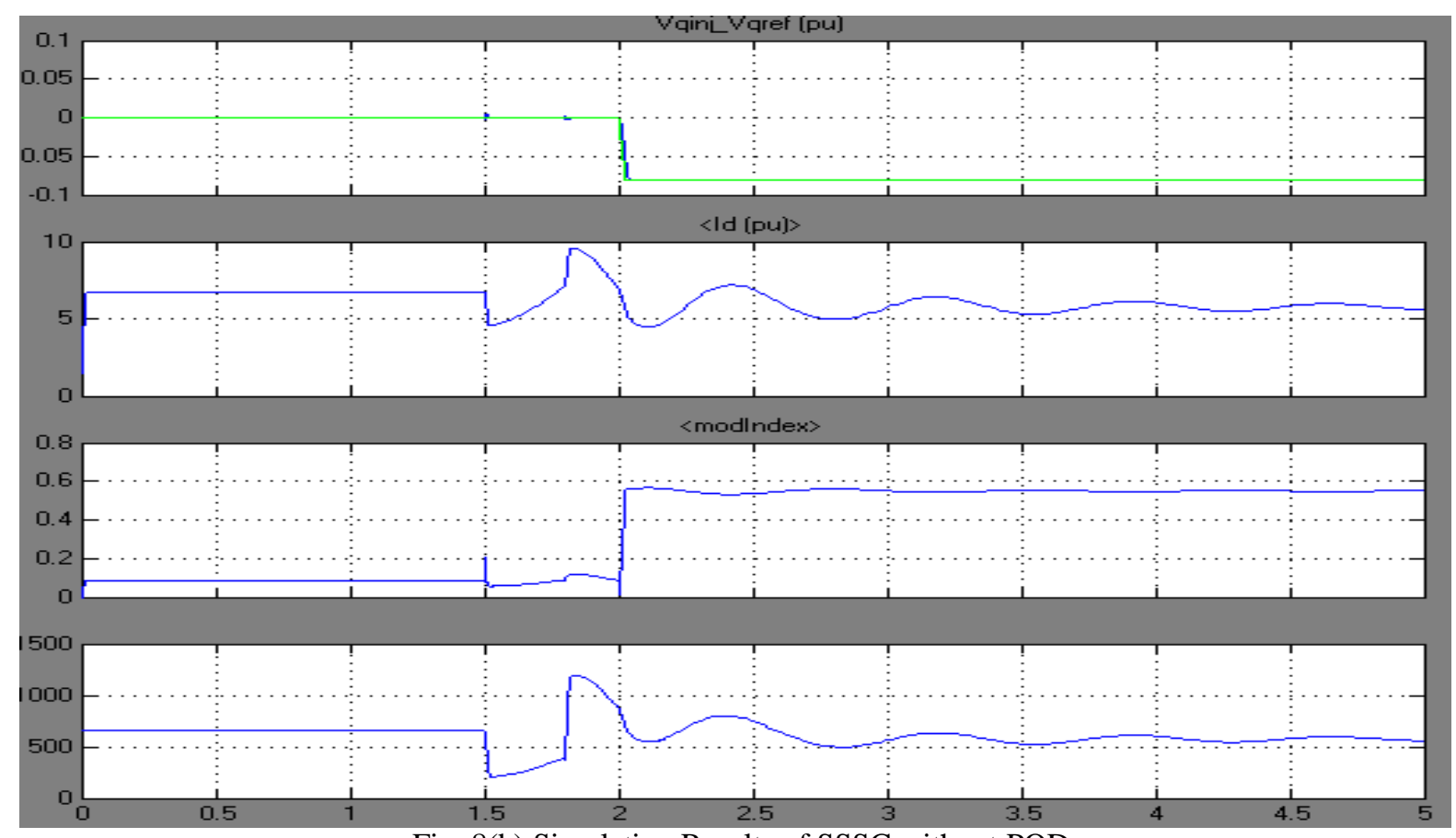

Fig. 8(b) Simulation Results of SSSC without POD
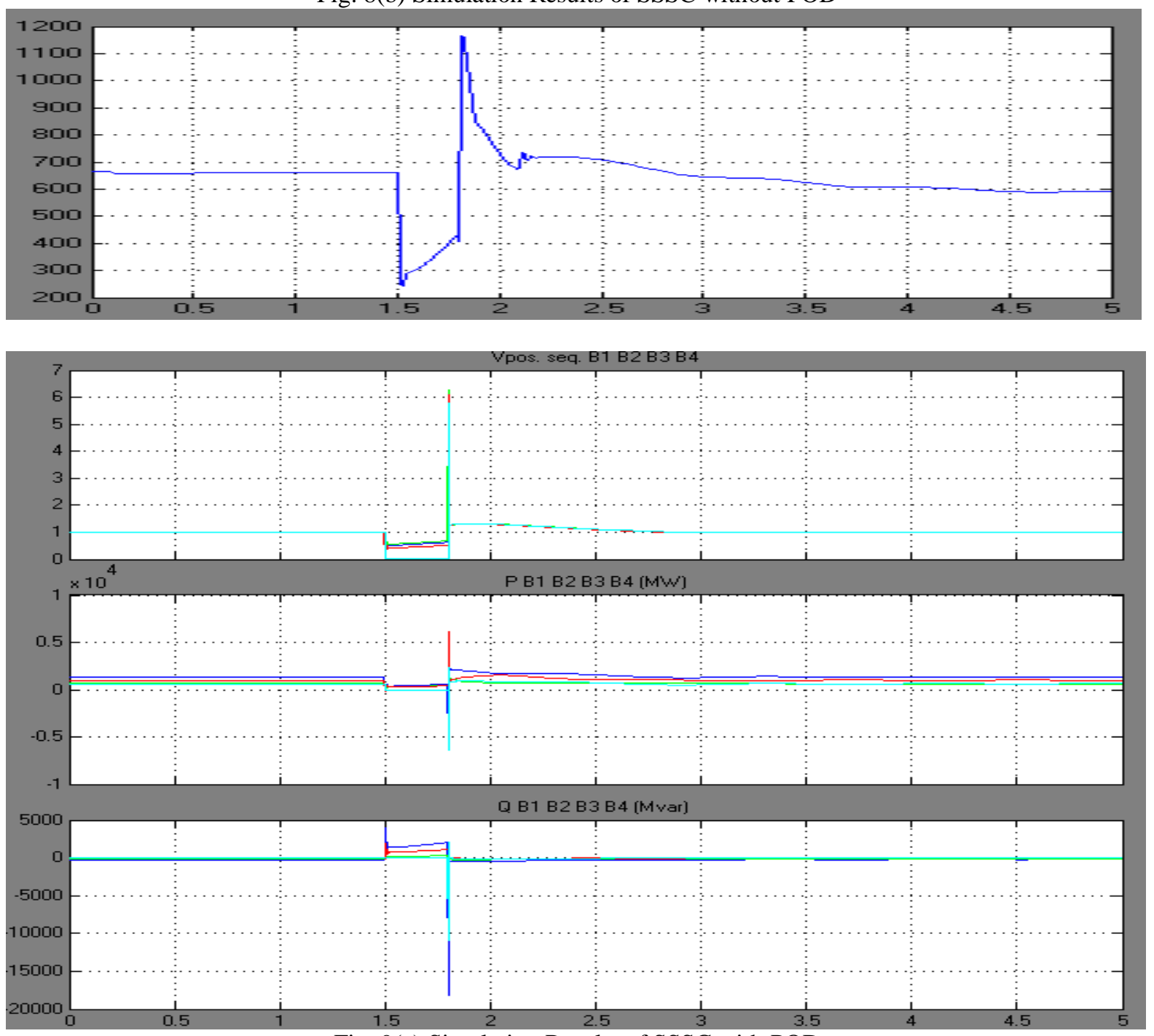

Fig. 9(a) Simulation Results of SSSC with POD 


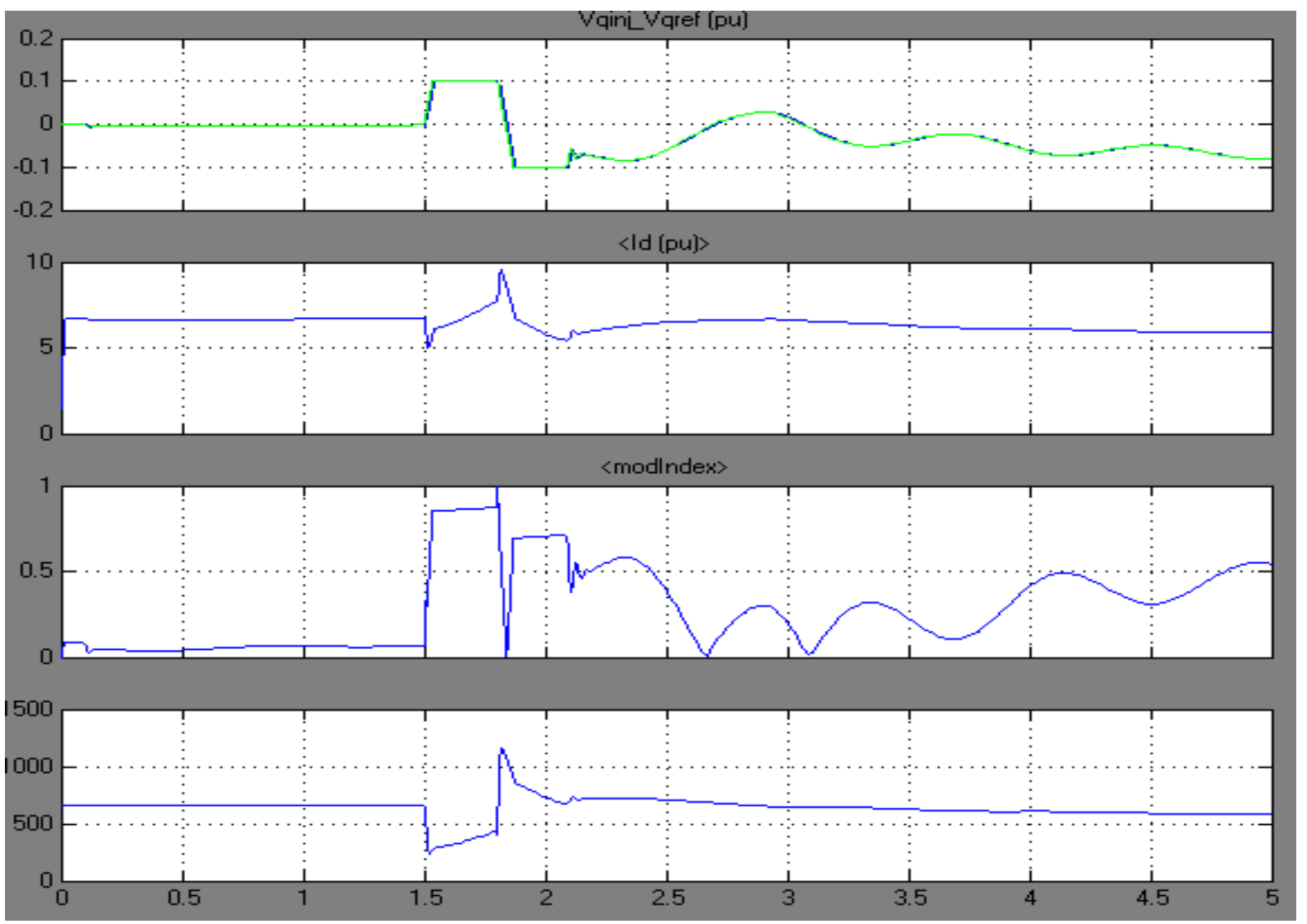

Fig. 9(b) Simulation Results of SSSC with POD

\subsection{SVC Controller}

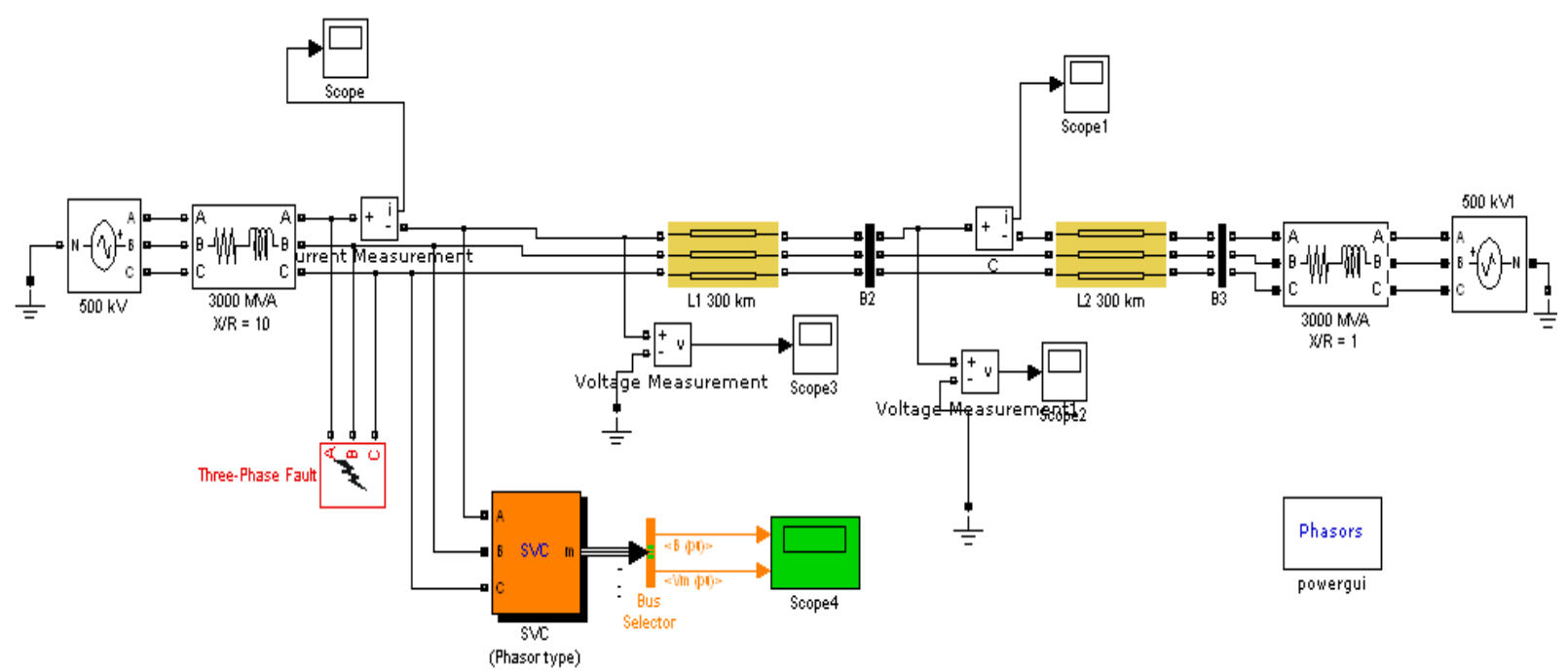

Fig. 10 Simulation Diagram of SVC Controller

A static var compensator (SVC) is used to regulate voltage on a $500 \mathrm{kV}, 3000$ MVA sytem. When system voltage is low the SVC generates reactive power (SVC capacitive). When system voltage is high it absorbs reactive power (SVC inductive). The SVC is rated +200 Mvar capacitive and 100 Mvar inductive. The Static Var Compensator block is a phasor model representing the SVC static and dynamic characteristics at the system fundamental frequency.

To see the SVC control parameters, open the SVC dialog box and select "Display Control parameters". The SVC is set in voltage regulation mode with a reference voltage Vref $=1.0 \mathrm{pu}$. The voltage droop is $0.03 \mathrm{pu} /$ 200MVA, so that the voltage varies from $0.97 \mathrm{pu}$ to 1.015 pu when the SVC current goes from fully capacitive to fully inductive. Double click now on the blue block to display the SVC V-I characteristic. 
The actual SVC positive-sequence voltage (V1) and susceptance (B1) are measured inside the 'Signal Processing' subsystem, using the complex voltages Vabc and complex currents Iabc returned by the Three-Phase V-I Measurement block.

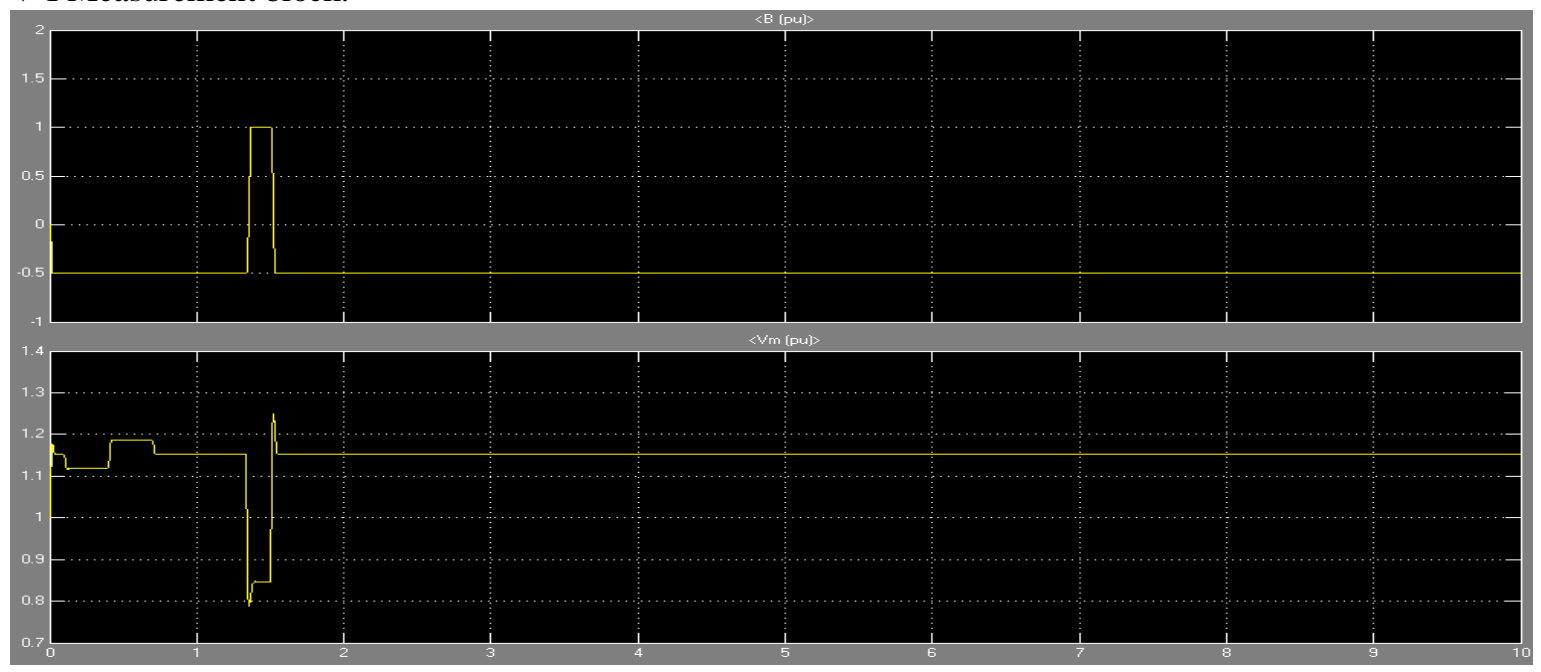

Fig. 11 Simulation results of SVC Controller

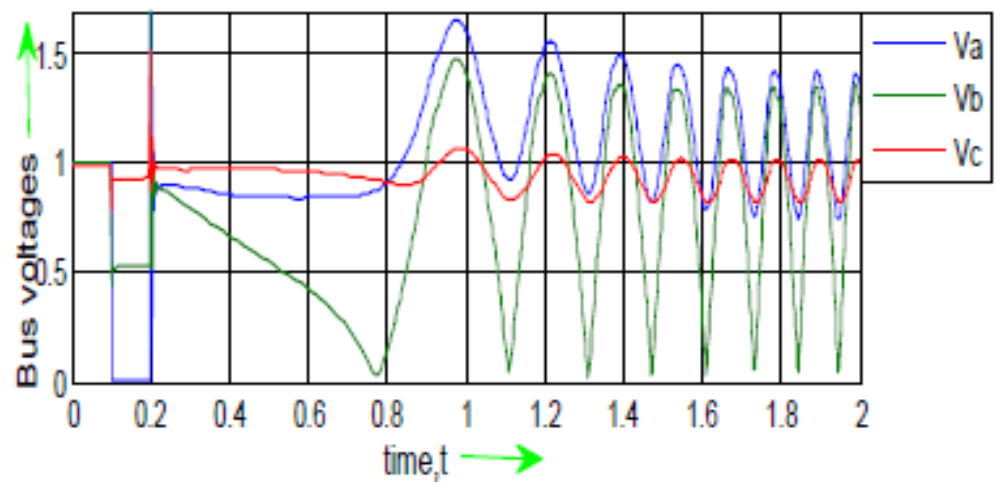

Fig. 12(a) Bus voltages in p.u for 1-phase fault (without SVC)

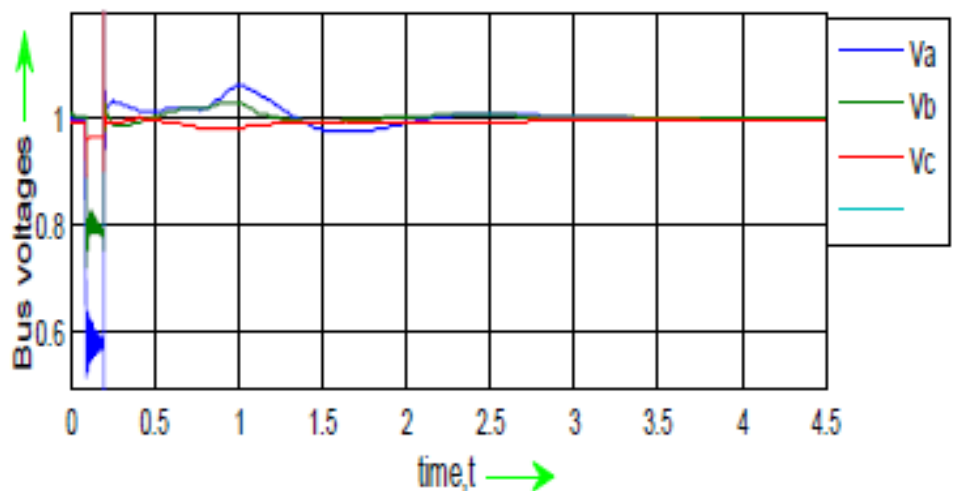

Fig. 12(b) Bus Voltages in p.u for 1-phase fault (with SVC)

\section{Comparison of SVC and SSSC with POD Controller}

The power system stability improvement i.e. voltage level, machine oscillation damping, real \& reactive power in a power system model of SVC and SSSC with proposed Power System Controller for faulted conditions. In combine, Power System Controller may be highly suitable as a SVC and SSSC with POD controller because of shorter stability time, simple designed, low cost \& highly efficient controller. These proposed Power System Controller can be applied for any interconnected multi-machine power system network for stability improvement.

The simulation of a two-machine power system model with Static synchronous series compensator (SSSC) based damping controllers in the presence of a three-phase short circuit fault and two phase ground fault 
are considered. The results show that the power system oscillations are damped out very quickly with the help of SSSC based damping controllers in few seconds. As the modulation ratio lies between zero and one, the dc voltage should not be lower than the maximum of the requested SSSC output phase voltage in order to obtain proper control. On the other hand, if the dc side voltage is too high, the rating of both the GTO valves and dc capacitor has to be increased, which means higher installation costs. Not only that, a higher dc side voltage means a lower amplitude modulation ratio and the lower modulation ratio results in higher harmonic distortion. Phase control allows the dc voltage to change according to the power system conditions, which is clearly advantageous, but it requires a more complicated controller and special and costly series transformers. The results show that the use of SSSC is having improved dynamic response and at the same time faster than other conventional controllers.

The most suitable location for SVC and SSSC with POD controller to control power flow and to improve voltage Profile. The improvement of voltage stability by SSSC and SVC would be better than that of either by STATCOM or TCSC. In case of without SVC and SSSC with POD, generation of reactive power can be increased, total real power losses are more, voltage stability index is high. In case of with SVC and SSSC with POD, generation of reactive power generation can be reduced, total real power losses are less, voltage stability index is low.

Table 1 Comparison of SVC and SSSC

\begin{tabular}{|l|l|l|}
\hline Issue & SVC & SSSC \\
\hline $\begin{array}{l}\text { V/I } \\
\text { characteristic }\end{array}$ & Good overvoltage performance Impedance & Good under voltage performance Voltage source \\
\hline Control range & $\begin{array}{l}\text { freely adjustable to any range by TCR/TSR /TSC } \\
\text { branches }\end{array}$ & Symmetrical \\
\hline Modularity & $\begin{array}{l}\text { TCR/TSR/TSC branches used in SVC and } \\
\text { TCSC/TPSC Redundancy Degraded mode } \\
\text { operation }\end{array}$ & $\begin{array}{l}\text { Same converter usable for various applications } \\
\text { UPFC, SSSC configurations are used in the CSC }\end{array}$ \\
\hline Response time & 2 to 3 cycle & 3 to 4 cycle \\
\hline $\begin{array}{l}\text { Transient } \\
\text { behavior }\end{array}$ & $\begin{array}{l}\text { Available before, during and after critical system } \\
\text { conditions }\end{array}$ & Self protecting at critical system faults \\
\hline $\begin{array}{l}\text { Space } \\
\text { requirements }\end{array}$ & $100 \%$ & 60 to $70 \%$ \\
\hline Availability & $>99 \%$ & 90 o $92 \%$ \\
\hline
\end{tabular}

\section{CONCLUSION}

This paper explains, the FACTS controllers that are used to mitigate the power quality problems. The standard FACTS controller for a particular type of problem is also given. The simulation results give the clear observation of how the FACTS devices improve the power quality. The simulation work is done on Static Var Compensator (SVC)and Static Synchronous Series Compensator(SSSC).SVC and SSSC are providing better power quality under variation of source voltage and when the system is suddenly loaded. The thesis includes the simulation results of the SVC and SSSC only. The future work given as the simulation results of the systems for various power quality problems with all remaining FACTS devices. Then it can be very easy to find an exact FACTS device for a particular type of power quality problem.

Installations of SSSC and SVC controllers at all suitable locations will naturally improve the voltage stability of a power system. But, keeping in mind, the cost of the controllers and the optimization task, the number of controllers and their sizes are minimized. Taking corrective actions to keep the system voltage secured under all possible line outage contingency will not be economical or it may not be necessary. Therefore, only the most critical line outage contingency is considered. The line outage is ranked according to the severity and the severity is taken on the basis of increased reactive power generation and real power losses. Outage of other lines has no much impact on the system and therefore they are not given importance

\section{REFERENCES}

[1] Molina, M.G. and P. E. Mercado, "Modeling of a Static Synchronous Compensator with Superconducting Magnetic Energy Storage for Applications on Frequency Control”, Proc. VIII SEPOPE, Brasilia, Brazil, 2002, pp. 17-22.

[2] Molina, M.G. and P. E. Mercado, "New Energy Storage Devices for Applications on Frequency Control of the Power System using FACTS Controllers,” Proc. X ERLAC, Iguazú, Argentina, 14.6, 2003, 1-6.

[3] Molina, M.G. and P. E. Mercado, "Evaluation of Energy Storage Systems for application in the Frequency Control", Proc. 6th COBEP, Florianópolis, Brazil, 2001, pp. 479-484.

[4] M. Noroozian, L. Angquist, M. Ghandhari, G. Andersson,1997, "Use of UPFC for Optimal Power Flow Control," IEEE Transactions on Power Delivery, 12(4), pp. 1629-1634.

[5] M. Ghandhari, G. Andersson, I.A. Hiskens, 2001, "Control Lyapunov Functions for Series Devices," IEEE Transactions on Power Delivery, 16(4), pp. 689-694. 
[6] P. Kumkratug, M.H. Haque, 2003, "Versatile Model of a Unified Power Flow Controller in Simple System," IEE Proc. Gener. Transm. \& Distrib., 150(2), pp. 155-161

[7] Habibur, Dr. Fayzur, Harun, 'Online voltage level im-provement by using SVC \& PSS' 'International Jour-nal of system \& simulation".Vol.06,No.02(Dec,2012) Issue(Received for publication)

[8] " MATLAB Math Library User's Guide", by the Math Works. Inc

[9] Singh, R. Singh, D.K. Simulation of D-STATCOM for Voltage Fluctuation Page(s): 225 - 230 Advanced Computing \& Communication Technologies (ACCT), 2012 Second International Conference.

[10] Hingorani N. G., Gyugyi L., Understanding FACTS concepts and Technology of flexible AC transmission systems, New York. IEEE Press, 2000.

[11] A. H. Norouzi and A. M. Sharaf, "Two control schemes to enhance the dynamic performance of the STATCOM and SSSC", IEEE Trans. Power Del., vol. 20, no. 1, pp.435-442, Jan. 2005.

[12] M. S. El-Moursi and A. M. Sharaf, "Novel Controllers for the 48-Pulse VSC STATCOM and SSSC for Voltage Regulation and Reactive Power Compensation", IEEE Transactions on Power Systems, vol.20,no.4,November 2005.

[13] N. Magaji and M.W. Mustafa, "Optimal Thyristor Control Series Capacitor Neuro-Controller for Damping Oscillations", Journal of Computer Science, Vol.5, No.12, 2009, pp. 983-990.

[14]. K.R. Padiyar, S. Krishna and NageshPrabhu, "On-line detection of loss of synchronism is large power systems", Int. Conf. on Power Systems, Katmandu, Nepal, November 2004.

[15] A.K.S.N. Polisetty, "Application of custom power devices for improving power quality", M.E. Project Report, Indian Institute of Science,July 2005. 